\title{
Current Advances in the Development of Decellularized Plant Extracellular Matrix
}

\author{
Yiwei Zhu' ${ }^{1,2 \dagger}$, Qi Zhang ${ }^{2 \dagger}$, Shengyu Wang ${ }^{1,2 \dagger}$, Jianfeng Zhang ${ }^{1}$, Shunwu Fan ${ }^{1}$ and \\ Xianfeng Lin ${ }^{1,2 *}$
}

' Department of Orthopaedic Surgery, Sir Run Run Shaw Hospital, Medical College of Zhejiang University, Hangzhou, China,

${ }^{2}$ Department of Orthopaedics, The First Affiliated Hospital of Wenzhou Medical University, Wenzhou, China

\section{OPEN ACCESS}

Edited by:

Martijn van Griensven,

Maastricht University, Netherlands

Reviewed by:

Mark Ahearne,

Trinity College Dublin, Ireland Kamal Hany Hussein,

Assiut University, Egypt

*Correspondence:

Xianfeng Lin

xianfeng_lin@zju.edu.cn

tThese authors have contributed equally to this work

Specialty section:

This article was submitted to Tissue Engineering and Regenerative Medicine,

a section of the journal Frontiers in Bioengineering and

Biotechnology

Received: 20 May 2021

Accepted: 30 June 2021

Published: 21 July 2021

Citation:

Zhu Y, Zhang Q, Wang S,

Zhang J, Fan S and Lin X (2021)

Current Advances in the Development of Decellularized Plant Extracellular

Matrix.

Front. Bioeng. Biotechnol. 9:712262.

doi: 10.3389/fbioe.2021.712262
An imbalance exists between the supply of organs for transplantation and the number of patients in the donor transplant waiting lists. Current use of autologous, synthetic, and animal-derived grafts for tissue replacement is limited by the low availability, poor biocompatibility, and high cost. Decellularized plant scaffolds with remarkable physical similarities to human organs have recently emerged and have been found to present favorable characteristics that make them suitable as an alternative biomaterial, such as a superficial surface area, excellent water transport and retention, pre-existing vascular networks, interconnected porosity, and a wide range of mechanical properties. In addition to their unique and superior biocompatibility, plant-derived scaffolds present the advantages of low production cost, no ethical or supply constraints, simple operation and suitability for large-scale production and research. However, there are still some problems and deficiencies in this field, such as immature decellularization standards and methods, insufficient research on the biocompatibility of plant extracellular matrix. At present, research on decellularized plant extracellular matrix is still in its infancy, and its applicability to tissue engineering needs to be further improved. In this review, the current research progress on decellularized plant scaffolds is reviewed, the problems to be solved and future research directions are discussed.

Keywords: decellularized, plant, extracellular matrix, biocompatibility, biomaterials

\section{INTRODUCTION}

More than 200,000 patients need an organ transplant, while only about $15 \%$ of them received a transplant. And this disparity between organs and patients who need a donor organ remains one of medicine's challenges (Author Anonymous, 2021). With the development of research, many materials from natural or artificial sources have been applied in transplantation, among which decellularized materials are considered as a promising biomaterial. At present, decellularized animal scaffold is the most widely used, in which all the cells are removed by physical, chemical or biological methods, and the components of extracellular matrix are retained as much as possible. Then, acellular scaffolds can be reseeded with human cells to produce an autologous graft (Badylak et al., 2009). However, decellularized animal scaffolds bring some problems, such as low production, high cost and ethical issues (Huerta et al., 2016). 
Recently, plant scaffolds have been widely studied as substitutes for animal acellular scaffolds. In 2014, apple hypanthium tissue was made into a natural cellulose fiber scaffold by decellularization because of its special internal structure composed of pores and air pockets, which supports growth of mammalian cells in vitro for 12 weeks (Modulevsky et al., 2014). In 2017, decellularized spinach leaves were obtained by retaining their vascular structures, which resemble mammalian vasculature (Gershlak et al., 2017). Since then, various plantbased tissues, including parsley, bamboo, Calathea zebrina, and Anthurium warocqueanum, have been decellularized as scaffold materials (Fontana et al., 2017). Because of the existence of a variety of tissue structures in the plant kingdom, plant-derived acellular scaffolds can simulate human organs according to the structural characteristics of plants (Gershlak et al., 2017). In addition to preserving the characteristics of animal structures, plant structures are characterized by their unique and biological compatibility, low production cost, freedom from ethical and supply constraints, simple operation and are suitable for largescale production and research (Gershlak et al., 2017). The modifiability and complete vascular system of plant-based tissues make them suitable for the growth of a variety of stem cells, and they present good prospects for use in heart regeneration (Gershlak et al., 2017) and bone tissue regeneration (Lee et al., 2019). However, there are still many problems with decellularized plant scaffolds, such as immunogenicity, biodegradability, immature decellularization standards, and methods. In this review, the current research progress of decellularized plant scaffolds is reviewed, and the existing problems and the future research directions are discussed.

\section{THE EXTRACELLULAR MATRIX IN PLANT}

The plant cell is the fundamental unit of structure and function of plant life, which is composed of protoplast and cell wall (Caffall and Mohnen, 2009). Protoplast is the general term for all substances in the cell wall and is mainly made up of cytoplasm, nucleus, cell membrane and organelle. In addition, the plant cell wall, also regarded as the extracellular matrix of plants, form the shape of plant tissues and organs, and plays an important role in intercellular communication and plant-microbe interactions. The plant cell wall is mainly made up of polysaccharides, of which cellulose is the major component (Caffall and Mohnen, 2009). Cellulose is organized into para-crystalline structures, which embedded in a rich polysaccharide matrix, including hemicelluloses and pectins, as well as structural lignin and structural glycoproteins in certain plants (Zablackis et al., 1995).

Cellulose is a kind of long-chain polysaccharide composed of 7,000-15,000 glucose monomer units and is rotated $180^{\circ}$ alternately, which is the major structural fiber in the plant. Cellulose molecules are arranged into microfibres with a diameter of approximately 3-4 nm (Hori et al., 2002; Peura et al., 2008; Fernandes et al., 2011). Cellulose has been widely used in regenerative medicine, such as cartilage (Müller et al., 2006;
Wegst et al., 2015), bone (Liuyun et al., 2009; Zaborowska et al., 2010), and wound healing (Czaja et al., 2006, 2007). After immersion in $\mathrm{Ca}(\mathrm{OH})_{2}$ solution, the cellulose was covered with a calcium phosphate layer, which is considered to be a novel scaffold structure for cartilage tissue engineering (Müller et al., 2006). Liuyun et al. (2009) used a freeze-drying method to make nano hydroxyapatite, chitosan, and carboxymethyl cellulose polymer into a new biodegradable composite scaffold material, which has a good prospect in the field of bone regeneration.

Xylan is a kind of heterogeneous polysaccharide found in the cell wall of plants. Xylan has been proved to enhance the phagocytic capacity of macrophages and induce lymphocyte proliferation, which is related to the initial inflammation after fracture injury (Zhou et al., 2010; Fang et al., 2012). Bush et al. (2016) combined the xylan (hemicellulose) and chitosan to form composite hydrogel, which is suitable for repairing large bone defects as a bone graft substitute.

Lignin is a biopolymer with a three-dimensional network structure formed by the interconnection of three phenylpropane units through ether bonds and carbon-carbon bonds, which mainly located between cellulose fibers (Ponnusamy et al., 2019). Lignin shows good antioxidant activity and excellent mechanical properties. Zhang et al. (2019) combined lignin, chitosan, and polyvinyl alcohol to form composite hydrogel, which has better antioxidant activity and scavenging ability of free radicals, and can accelerate wound healing in mice.

Since there is a wide variety of plant structures in the plant kingdom, decellularized plant- derived scaffolds can be selected according to their own structure and properties to simulate the diversity of mammalian tissues.

\section{OVERVIEW OF NATIVE PLANT DECELLULARIZATION PROTOCOLS}

In the process of decellularization, the cellular components of the native plant tissue are removed and the decellularized scaffold is obtained. Ideally, all cellular components should be removed, while maximizing the preservation of plant extracellular matrix, as well as the plant's structural and mechanical properties. In addition, toxic agents used in the decellularization regimen should be removed to ensure the biocompatibility of the scaffold. The existing decellularization protocols are shown in Table $\mathbf{1}$ and brief overview of the decellularization process is shown in Figure 1. Plant cuticle wax consists of a layer of white crystals covering on the surface of land plants, which inhibits the water loss from the surface of plants and protects plants from pathogen invasion. It is a hydrophobic organic mixture composed of superlong chain fatty acids and their derivatives, including alkanes, primary alcohols, and ketones, which can be extracted by using organic solvents. Therefore, in the process of decellularization of some plant tissues, hexane is used to remove the epidermal wax (Gershlak et al., 2017).

\section{Detergent}

The porous structure of most plants is conducive to decellularization because it allows rapid exchange of detergents, 
TABLE 1 | Representative protocols used for plant decellularization.

\begin{tabular}{|c|c|c|c|c|}
\hline Number & Decellularization method & Tissue type & Material size & References \\
\hline (1) & $\begin{array}{l}10 \% \text { sodium dodecyl sulfate (SDS) for } 5 \text { days } \\
1 \% \text { non-ionic surfactant in } 10 \% \text { bleach solution until visibly } \\
\text { cleared (visual comparison) }\end{array}$ & F. hispida & 8 mm disk samples & Adamski et al. (2018) \\
\hline (2) & $\begin{array}{l}5 \% \mathrm{NaClO} \text { and } 3 \% \mathrm{NaHCO}_{3} \text { until visibly cleared (visual } \\
\text { comparison) }\end{array}$ & F. hispida & 8 mm disk samples & Adamski et al. (2018) \\
\hline (3) & $\begin{array}{l}10 \% \text { sodium dodecyl sulfate (SDS) for } 5 \text { days } \\
\text { clearing solution ( } 0.1 \% \text { TritonX-100 and } 10 \% \text { sodium } \\
\text { chlorite) for } 2 \text { days }\end{array}$ & Spinach and parsley & $1 \mathrm{~cm}$ squares & Gershlak et al. (2017) \\
\hline (4) & $\begin{array}{l}10 \% \text { sodium dodecyl sulfate (SDS) in water for } 5 \text { days } \\
0.1 \% \text { Triton-X-100 in a } 10 \% \text { solution of bleach for } 2 \text { days }\end{array}$ & $\begin{array}{l}\text { Calathea zebrina, Anthurium } \\
\text { warocqueanum, } \\
\text { Anthurium magnificum, Solenostemon, } \\
\text { Vanilla, Bamboo }\end{array}$ & $8 \mathrm{~mm}$ disk & Fontana et al. (2017) \\
\hline (5) & $0.5 \%$ sodium dodecyl sulfate (SDS) & $\begin{array}{l}\text { Apple, Broccoli, Sweet pepper, Carrot, } \\
\text { Persimmon, and Jujube }\end{array}$ & $1 \times 1 \mathrm{~cm}$ & Lee et al. (2019) \\
\hline (6) & $1 \mathrm{mg} / \mathrm{mL}$ DNase I for 30 mins & $\begin{array}{l}\text { Tobacco BY-2 cells, Rice cells Tobacco } \\
\text { hairy roots }\end{array}$ & 1 & Phan et al. (2020) \\
\hline (7) & $\mathrm{ScCO}_{2}$ and $2 \%$ peracetic acid (PAA) & $\begin{array}{l}\text { Spinach leaves, Parsley stems and } \\
\text { Celery stalks }\end{array}$ & $\backslash$ & Harris et al. (2021) \\
\hline
\end{tabular}

The decellularization protocol of different plants can be adjusted based on the existing protocols according to the size and shape of plants.

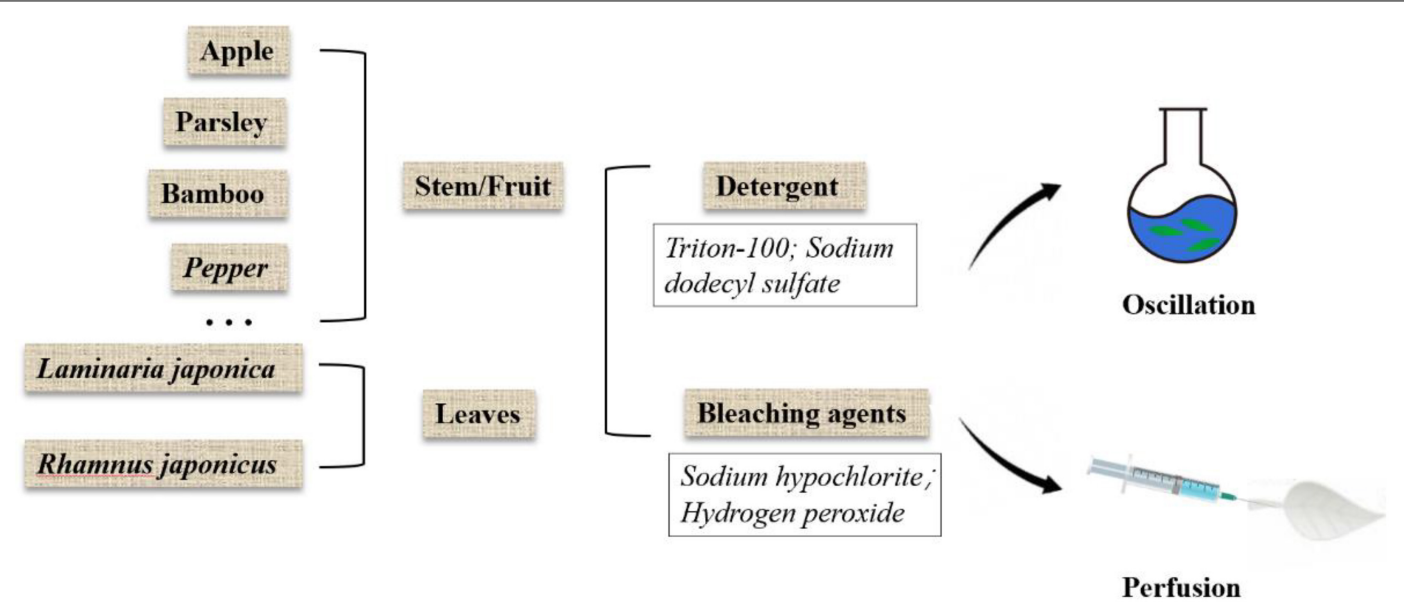

FIGURE 1 | Overview of plant decellularization methods.

buffers, and media without the use of a perfusion system. Therefore, the decellularized cellulose scaffold can be made quickly by using only detergent. SDS is an anionic detergent that dissolves the cell membrane and nuclear membrane by breaking the bonds between the cell membrane and cytoplasmic proteins (Johnson, 2013). Because of the minimal physical agitation, SDS is likely to be suitable for most plant species, especially for cleaning entire leaves (Adamski et al., 2018).

\section{Bleaching Agents}

Previous research has shown that leaves simmered in a solution of bleach (such as $\mathrm{NaClO}$ ) and sodium bicarbonate help to separate vascular tissue from soft tissue, which carried out in the 17th and 18th centuries (Seba, 1730). These experiments soak plant tissues, such as leaves and fruits, in water until the soft tissues decompose naturally. This method is suitable for fragile tissue because it avoids extensive damage to the soft tissue structure. It has also been reported that this method has less effect on cell growth than the detergent-based method (Gershlak et al., 2017).

\section{Enzyme}

Nuclease, which has been widely used in the process of animal tissue decellularization, provide high specificity in removing genetic material. Recently deoxyribonuclease (DNase) was firstly used in tobacco and rice (Phan et al., 2020). Phan et al. decellularized lyophilized tobacco and rice cells with $1 \mathrm{mg} / \mathrm{mL}$ DNA enzyme, and detergent method $(0.25 \%$ sodium dodecyl sulfate or $0.1 \%$ Triton X-100) was used as control to investigate the effect of different surfactant treatments on DNA removal and protein retention. 
Result showed that plant cells and tissue can be completely decellularized with DNase, with substantial protein retention (Phan et al., 2020).

\section{Supercritical Carbon Dioxide}

Supercritical carbon dioxide $\left(\mathrm{ScCO}_{2}\right)$ refers to the special state where carbon dioxide behaves as neither a gas nor a liquid under critical conditions (temperature $=31.26^{\circ} \mathrm{C}$, pressure $=27.9$ atm). $\mathrm{ScCO}_{2}$ has been widely used in food industry, biology, pharmacy, and other fields because of its mild reaction conditions, non-toxicity, residue free reaction process, and easy operation (Guler et al., 2017). The mechanism of supercritical carbon dioxide for decellularization is still controversial. The hypothesis that high pressures burst the cells during treatment and cell removal was achieved by rapid depressurization has not been widely accepted and has been largely proved false. Harris et al. supposed that the pressure dissolves the carbon dioxide into the liquid phase, which allows it to penetrate the walls and membranes of plant cells. This transfer of $\mathrm{ScCO}_{2}$ reduces the intracellular $\mathrm{pH}$ through the formation of carbonic acid, which leads to disruption of cell metabolism and removal of essential enzymes. In addition, the combined application of supercritical carbon dioxide and co-solvents (like peracetic acid) can significantly improve the efficiency of decellularization (Harris et al., 2021).

\section{MECHANICAL PROPERTIES AND STRUCTURES OF DECELLULARIZED PLANT SCAFFOLDS}

Due to the diversity of plant species in nature, their mechanical strength varies greatly, and some of them are highly similar to human tissues and organs in structure, shown in Figure 2. Some highly vascularized plant tissue, such as spinach leaves, may be more suitable for highly vascularized tissue (Gershlak et al., 2017), such as heart tissue, while the cylindrical hollow structure of plant stems may be more suitable for arterial transplantation. In addition, the high mechanical strength and geometric shape of wood make it a good application prospect in bone engineering.

\section{Mechanical Analysis of Decellularized Plant Scaffolds}

The compositions of these different polysaccharides depend on the types of plant tissue, which endow them with specific physical properties. The modulus and compressive strength of plant-based materials span the whole range. The following Table 2 shows the mechanical properties of common plant decellularized scaffolds. The compression modules of decellularized apple tissue were similar to that of human adipose tissue, such as breast $(2 \mathrm{kPa})$ and abdominal tissue ( $3 \mathrm{kPa}$ ). The compression modulus of carrot-derived scaffolds was $43.43 \mathrm{kPa}$, comparable to those scaffolds that have been widely proposed for non-load bearing bone scaffolds
(Peng et al., 2019; Contessi Negrini et al., 2020). Hence, carrot-derived decellularized scaffolds may be applied to bone fillers under non-weight-bearing conditions. Decellularized celery was able to withstand $20 \%$ strain without failure, which is similar to maximum deformation value of natural tendon in vivo (Mathew et al., 2012; Contessi Negrini et al., 2020). In addition, the directional morphology of celery tissue has a strong resemblance with natural tendon tissue. Although decellularization process reduces the mechanical properties of plant tissue, they are still within the range of natural human tissues.

\section{Pore Sizes of Plant Scaffolds}

For pore size, $200-250 \mu \mathrm{m}$ was the most suitable pore size for the growth and adhesion of human cells. The pore sizes of different plants vary greatly (from 20 to $800 \mathrm{~mm}$ ), and are shown in Table 3. Before and after the process of decellularization, the changes of pore size of different types of plants are different, which may be related to the mechanical strength of plants (Lee et al., 2019). Hard plant tissues, such as bamboo and other stems, have little change in pore size before and after decellularization, or even become smaller; soft tissues, such as leaves, the structure becomes slack due to the long period of oscillation and washing during the decellularization process, resulting in the large increase of pore size. Lee et al. inoculated human induced pluripotent stem cells (HiPSCs) on several decellularized plant scaffolds, including apples, carrots, and sweet peppers. They found that only decellularized apple scaffolds could support the cell growth and reproduction, while the multiplication and growth of pluripotent stem cells on other scaffolds were poor, which indicated that the appropriate pore size is the key condition for supporting cell growth even if the scaffold components were similar (Lee et al., 2019).

\section{Similarity in Vascular Network Between Plant and Human Tissues}

At present, the lack of functional vascular tissue is an important obstacle to tissue engineering transplantation, which leads to poor prognosis of tissue after transplantation. Lee et al. found that although plants and animals used very different methods to deliver fluids and nutrients, their vascular networks were remarkably similar. Plant vascular systems follows Murray's Law (McCulloh et al., 2003), which is also the physiological law describing the network design of the human cardiovascular system (Murray, 1926). In their study, the vascular network in the spinach leaves remained intact and could support the flow of red blood cells even after decellularization. By combining vascularized leaves with perfusion-based decellularization, natural vascularized scaffolds can be provided. However, Jansen et al. found that the vascular system of plant leaves might not be suitable for recellularization. Although cells can grow in the petiole, they cannot enter the vascular system of leaves through the petiole because the vascular is actually located in the parenchyma near the petiole 


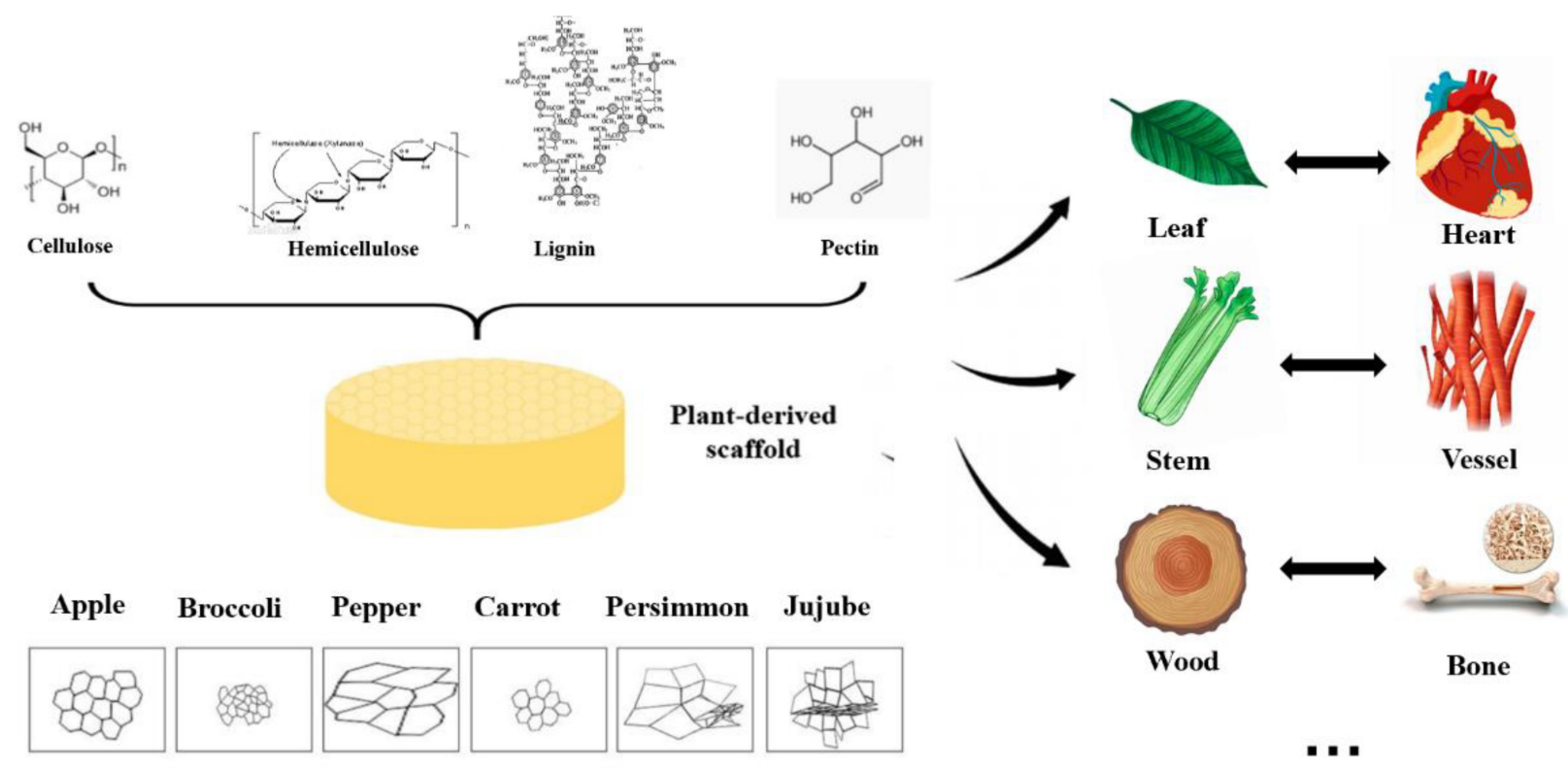

FIGURE 2 | Structure, pore size and similarities between human organs and plant scaffolds: Plant scaffolds are basically composed of cellulose, hemicellulose, lignin and pectin, and the porosity size and pore shape of different plant tissues are quite different. A scaffold with potential for organ regeneration can be obtained by selecting the plant tissue that is similar to the human organ tissue in physical properties for decellularization treatment.

TABLE 2 | Mechanical properties of existing plant scaffolds.

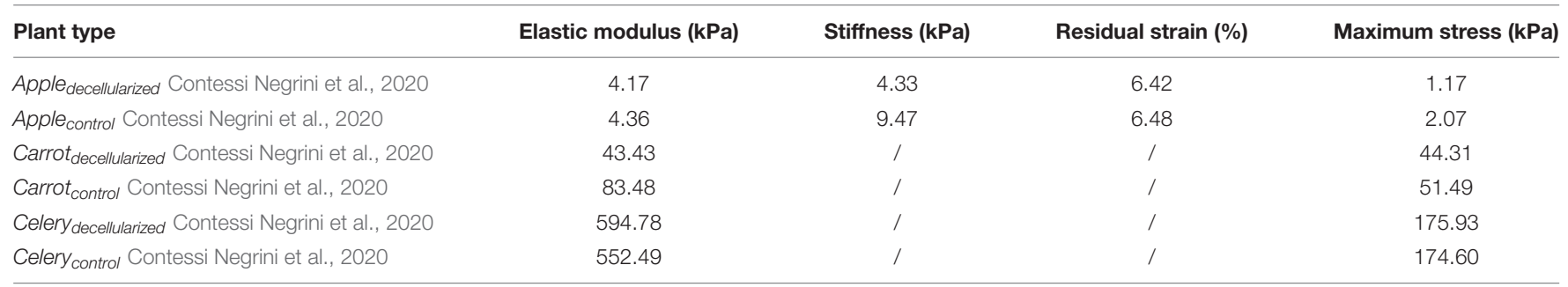

TABLE 3 | The pore size of representative plants before and after decellularization.

\begin{tabular}{lcc}
\hline Plant type & & Pore size $(\mu \mathrm{m})$ \\
\cline { 2 - 2 } & Before decellularization & After decellularization \\
\hline Bamboo Fontana et al., 2017 & 81.1594 & 78.2609 \\
Anthurium warocqueanum Fontana et al., 2017 & 40.5797 \\
Calathea zebrine Fontana et al., 2017 & 39.1305 \\
Orchid's pseudobulb Fontana et al., 2017 & 63.7681 \\
Parsley Fontana et al., 2017 & 23.1884 \\
Vanilla Fontana et al., 2017 & 86.9565 \\
Apple Lee et al., 2019 & 321.951 \\
Broccoli Lee et al., 2019 & 117.073 \\
Jujube Lee et al., 2019 & 126.829 \\
Carrot Lee et al., 2019 & 258.537 \\
Persimmon Lee et al., 2019 & 473.171 \\
Sweet pepper Lee et al., 2019 & 809.756
\end{tabular}

and is not connected to the petiole cavity (Jansen et al., 2020). Therefore, although plant decellularized scaffolds have some similarities with human organs in general morphology, they still have slight differences, resulting in the fact that only simple-structured organs and tissues can be republicated. This is one of the disadvantages 
of plant decellularized scaffolds compared with animal decellularized scaffolds.

\section{CURRENT OBSTACLES TO THE APPLICATION OF PLANT ECM}

\section{Biodegradability of Plant Scaffolds in vivo}

Cellulose is a kind of natural glucose linear polymer connected by 1,4-glucosidic bonds and hydrogen bonds. This is the reason why cellulose has high crystallinity, low solubility, and poor degradation in vivo (Miyamoto et al., 1989). Cellulose can be degraded by microorganisms and fungi in nature. However, because of the lack of appropriate enzymes to digest plant cellulose in mammals and humans, the degradation of decellularized plant scaffolds in vivo is also an urgent problem to be solved. Lee et al. (2019) found plant-derived scaffolding implants remained intact after 8 weeks.

At present, some studies have made preliminary progress in the degradation of cellulose in vivo. Entcheva et al. (2004) mixed cellulose scaffolds with cellulase (endoglucanase, exoglucanase, and $\beta$-glucosidase) for hydrolysis pretreatment, which can obtain different degrees of biodegradable and biocompatible cellulose scaffolds. Recently, Horn et al. (2012) found a new group of enzymes, classified as carbohydrate binding modules 33 (CBM33) and glycoside hydrolase 61 (GH61), which can catalyze the oxidative cleavage of polysaccharides. However, study has shown that cellulose enzymes have negative effect on the adhesion of some cells (Entcheva et al., 2004). The mechanical properties of plant scaffolds may be decreased during pre-hydrolysis and the degradation rate of the pretreated scaffolds in vivo is difficult to control due to the different degree of hydrolysis. In addition, whether the microstructural changes of the pre-hydrolyzed scaffolds will cause unexpected inflammatory responses in vivo is still unknown, which needs further study.

Another way to induce the degradability of cellulose is oxidation. Oxidized cellulose can be generated by various oxidizing agents, such as $\mathrm{NaClO}_{2}$ and $\mathrm{CCl}_{4}$ (Kumar and Yang, 2002; Zimnitsky et al., 2004; Saito et al., 2007). Oxidized cellulose can be degraded by hydrolysis, by mediated hydrolytic enzymes present in the serum supplement of cell culture media in vitro and in vivo (Dimitrijevich et al., 1990b). Aswathy et al. oxidized bamboo stems with different concentrations of sodium periodate. Sodium periodate can selectively cleavage the $\mathrm{C} 2-\mathrm{C} 3$ bond of the polysaccharide chain to convert hydroxyl group to dialdehyde. X-ray-diffraction (XRD) spectrum showed that the amorphous matrix of cellulose was increased and the crystallinity decreased after oxidation. Significant degradation of oxidized cellulose (70\%) was observed after 7 days of subcutaneous implantation in mice compared with unoxidized scaffolds. At the same time, the oxidized cellulose is conducive to protein adsorption, thus promoting cell adhesion and its function. This may be due to the covalent bond between the amino group in the protein and the aldehyde group on the surface of the fiber (S H et al., 2021).

However, there are still several problems to be solved about the degradation of plant scaffolds. Although cellulose is the main component in plant ECM, degradation of other components (such as lignin and pectin) has not been studied yet, and the in vivo response of the entire decellularized plant tissue is also unclear.

\section{Immunogenicity of Plant Decellularized Scaffolds}

Because of the relatively conservative nature of animal ECM, the main substances that cause immune rejection during the transplantation of animal-derived decellularized scaffolds are $\alpha$-gal and MHC, which do not exist in plants. In contrast, different types and different parts (the rhizome and leaf) of plant extracellular matrix components, especially plant proteins, vary greatly, which makes it challenging to study the immunogenicity of plant scaffolds. Phan et al. performed THP-1 derived macrophage activation experiments to assess the potential of transgenic tobacco cell-derived extracellular matrix to induce TNF- $\alpha$ secretion as a readout for immune cell activation. Result shows that treating THP-1-derived macrophages with the BY2 cell-derived matrices directly for $48 \mathrm{~h}$ resulted in increased TNF- $\alpha$ secretion, which may be induced by the phagocytosis of small particle. But the leachable components from the BY2 cell-derived matrix, such as potential proteins, do not induce activations of macrophage (Phan et al., 2020). After subcutaneous embedding of oxygenated decellularized bamboos in mice, a large number of cell infiltration, especially macrophages, were observed, which might be related to the degradation of scaffolds. The oxidized scaffold may attract more macrophages due to its high hydrophilicity and amorphous properties. Macrophages secrete vascular endothelial growth factor, fibroblast growth factor, and platelet-derived growth factor, and initiate the process of vascular germination, anastomosis, and maturation, thus vascular formation can be seen around the scaffold, indicating its ability to facilitate the natural process of regeneration (S H et al., 2021). Modulevsky et al. implanted the cellulose scaffolds obtained from decellularized apples (proteins completely removed) under mice skin, and histological analysis revealed a typical foreign body reaction to the scaffold at 1 week. However, the immune response was observed to disappear gradually at 8 weeks. By 8 weeks, there was no immune response in the surrounding dermis tissue, and active fibroblast migration was observed in the cellulose scaffold (Modulevsky et al., 2016).

In general, the immune responses of acellular plant scaffolds in vivo have not been systematically evaluated. For example, immunohistochemical staining of macrophage phenotypes is necessary to understand its role in immune response and vascularization. M1 macrophages promote the killing of pathogens and increase the levels of cells associated with typical inflammatory symptoms, especially chronic inflammation. While M2 macrophages are considered as anti-inflammatory macrophages, which can promote immune regulation, tissue repair and tissue remodeling (Badylak and Gilbert, 2008). 


\section{Effects of Decellularization Protocol}

Various protocols and reagents are used in the production of decellularized scaffolds to remove the nuclei and cellular content from tissues or organs while preserving the ECM structure. The decellularized scaffolds treated with detergents such as SDS were found to have cytotoxic effects due to the presence of residual SDS in the ECM (Caamaño et al., 2009). Therefore, thorough cleansing of the tissue is necessary to maintain the bioactivity of the acellular matrix (Syed et al., 2014). However, extensive cleaning procedures may reduce the mechanical properties of plant scaffolds and destroy the integrity of scaffolds. In addition, the Raman Spectroscopy and ATR-FTIR studies have shown that SDS has adverse effects on the ultrastructure of ECM in the process of decellularization of animal scaffolds, which may induce an immune response (Nara et al., 2016). The immune response may be triggered by exposure to the C-terminal, helical and $\mathrm{N}$-terminal peptides of the collagen layer. But the effect of detergents on specific plant ECM is not yet clear due to the diversity of plant species.

\section{Immunogenicity of Remaining Cell Debris}

At present, a clear scientific basis for the decellularized plant scaffold criteria is still lacking. Studies at present have mainly adopted the standard of animal decellularized scaffolds: DNA content of $<50 \mathrm{ng}$ double-stranded DNA/mg ECM (Chakraborty et al., 2020). Generally, Safranin and Fast Green are required to confirm the complete elimination of nucleus.

\section{Immunogenicity of Plant Protein}

During their long evolutionary histories, the sequences and structures of the proteins of plants and animals have become quite different. Important components of animal ECMs are proteoglycans (PGs), which is formed by covalently linking one or more glycosaminoglycans (GAGs) chains on a core protein (Frantz et al., 2010; Kular et al., 2014; American Association of Neurological Surgeons et al., 2018). Animal extracellular matrixes also have a large content of proteins, such as collagens, elastin, fibronectin, laminins, and glycoproteins. In the plant extracellular matrix, however, proteins are merely minute components of the plant cell wall and are trapped in the complex network of polysaccharides. Due to the diversity of plant species and the limitations of plant protein extraction, it is estimated that only a few proteins (less than 5\%) have clear biochemical activity, localization, and biological effects (Albenne et al., 2014; Niehaus et al., 2015).

Some plant proteins, mainly cereal proteins, have been used to construct scaffolds (Reddy and Yang, 2011). Soy protein films crosslinked with glyoxal and tannic acid were studied as potential membrane materials and have been proved to have good biocompatibility in vitro (Silva et al., 2003). However, some have been proved to be immunogenetic, such as zein and sericin (Altman et al., 2003; Hurtado-López and Murdan, 2006). Hence, the potential immunogenicity of plant protein-based materials needs further study. First, analysing the protein compositions and content of plants before and after decellularization is a must, which is not available in most current studies. Second, conducting a comprehensive evaluation of the bioactive proteins abundant in specific plant tissue, including the evaluation of biocompatibility and bioactivity. T-cell proliferation and pluripotent myeloid stem cell (PMSC) assay can be used to determine the cytocompatibility of plant proteins. PMSC assay co-cultures the protein with human peripheral blood mononuclear cells (PBMCs) and investigate the upregulation of dendritic cells (DC) maturation markers, such as CD83, CD80, and CD86. For different bioactive plant proteins, targeted in vitro experiments can be carried out. Then, moderately retaining the identified substances in plant

TABLE 4 | Review of plant scaffold recellularization protocols.

\begin{tabular}{|c|c|c|c|c|}
\hline Plant type & Cell type & Research Purpose & Result & References \\
\hline \multirow[t]{3}{*}{ Apple } & Human epithelial cells & Adipogenic differentiation & $\begin{array}{l}\text { The intracellular lipid accumulation typical of } \\
\text { adipocytes is observed }\end{array}$ & Silva et al. (2003) \\
\hline & $\begin{array}{l}\text { 3T3-L1 murine cell line (ECACC } \\
\text { No 86052701) }\end{array}$ & & & \\
\hline & Induced pluripotent stem cells & Osteoblastic differentiation & $\begin{array}{l}\text { Mineralizing nodules are observed, osteogenic } \\
\text { markers (OCN, COL-1) are detected }\end{array}$ & Harris et al. (2021) \\
\hline \multirow[t]{4}{*}{ Spinach leaf } & Prostate cancer cells & $\begin{array}{l}\text { Tumor cell response to the } \\
\text { decellularized spinach leaf } \\
\text { scaffolds }\end{array}$ & $\begin{array}{l}\text { YAP/TAZ signaling downregulation, cellular } \\
\text { morphology alteration, and proliferation rate } \\
\text { decrease }\end{array}$ & Lacombe et al. (2020) \\
\hline & Melanoma cells & & & \\
\hline & $\begin{array}{l}\text { Human umbilical vein } \\
\text { endothelial cells }\end{array}$ & $\begin{array}{l}\text { Leaf vasculature } \\
\text { endothelialisation }\end{array}$ & Remain viable and adhered & Gershlak et al. (2017) \\
\hline & $\begin{array}{l}\text { Human pluripotent stem cell- } \\
\text { derived cardiomyocytes }\end{array}$ & Function examination & Spontaneously contract at Day 5 & Gershlak et al. (2017) \\
\hline Carrot & Pre-osteoblast cell (MC3T3-E1) & Osteogenic differentiation & $\begin{array}{l}\text { Nano-sized particles are detected on the surface of } \\
\text { differentiation-induced cells }\end{array}$ & $\begin{array}{l}\text { Contessi Negrini et al. } \\
(2020)\end{array}$ \\
\hline Green onion & $\begin{array}{l}\text { Human skeletal myoblasts } \\
\text { (HSMCs) }\end{array}$ & Muscle differentiation & $\begin{array}{l}\text { Support growth, proliferation, and differentiation of } \\
\text { human skeletal muscle and provide the necessary } \\
\text { alignment of myotubes required for enhanced } \\
\text { functional contractility of muscle tissue }\end{array}$ & Cheng et al. (2020) \\
\hline Bamboo & Mesenchymal stem cells & Osteogenic differentiation & $\begin{array}{l}\text { High alkaline phosphatase activity and osteocalcin } \\
\text { release }\end{array}$ & S H et al. (2021) \\
\hline
\end{tabular}


tissues to obtain a bioactive plant scaffold, by adjusting the decellularization protocol (e.g., by reducing the concentration of detergent or shortening the decellularization time), may be a possible way to obtain a bioactive plant scaffold.

\section{APPLICATION OF PLANT DECELLULARIZED ECM}

\section{Recellularization of Decellularized Scaffold}

The good adhesion, proliferation, and function of human cells on the plant ECM scaffold determine the successful application of decellularized plant tissues in human tissue culture. At present, decellularized plant scaffolds mainly recellularized with embryonic stem cells or mesenchymal stem cells, which have a good prospect in cardiovascular regeneration biology and bone tissue regeneration biology (Gershlak et al., 2017; Fontana et al., 2017; Table 4 and Figure 3). Fontana et al. (2017) planted human mesenchymal stem cells (MSCs) and human skin fibroblasts (hDFs), respectively, after biomineralization and tripeptide Arginine-Glycine-Aspartate (RGD) modification of parsley stem cells. It was observed that MSCs and hDFs could proliferate greatly at the same time (Fontana et al., 2017), and Gershlak et al. (2017) seeded human umbilical vein endothelial cells and human pluripotent stem-cell derived cardiomyocytes on the decellularized spinach scaffold modified with fibronectin. It was observed that the adherent human umbilical vein endothelial cells (HUVECs) arranged with the inner vessel wall and survived; within 21 days, the spontaneous contraction of embryonic stem cell derived cardiomyocytes (HPS-CMs) was observed when it attached to the surface of the leaf scaffold.
However, because of the removal of the most part of extracellular matrix and the lack of cell adhesion molecules, the obtained cellulose scaffolds perform poorly in cell adhesion and have to be modified with some amino acids to support cell growth, such as RGD and poly-L-lysine (PLL) (Fontana et al., 2017). This limitation can also be attributed to the lack of research on plant extracellular matrix and plant proteins, as mentioned above. In addition, since the plant scaffolds lack the environment or the corresponding cytokines to induce human cell differentiation, covering the plant decellularized scaffolds with a differentiation inducing coating may be the current research direction, such as vascular-induced differentiation or bone-induced differentiation.

\section{Decellularized Plant Scaffold for Cartilage and Bone Tissue Construction}

Decellularized plant scaffolds have not been reported for cartilage engineering, but some plant extracts have been proved to have the potential to promote cartilage formation. In 2018, a plantderived polysaccharide carboxymethyl cellulose (CMC) was sulfated and combined with previous research results to prepare a macroporous framework for injection (Waghmare et al., 2018). With its unique shape memory characteristics and its adhesion to growth factors, the scaffold effectively simulates the complex process of natural cartilage regeneration in cartilage repair.

Decellularized plant scaffolds have a good prospect in promoting osteogenesis. Lee et al. planted pluripotent stem cells into decellularized apple scaffolds. After $96 \mathrm{~h}$ of culture, the surviving cells still expressed stem cell markers (OCT3/4, Sox2, Nanog, Lin28, dppb5, tdgf1, and ssea4), and their levels were similar to those of iPSCs cultured in 2D medium, which meant that HiPSCs retained pluripotency in the scaffolds.

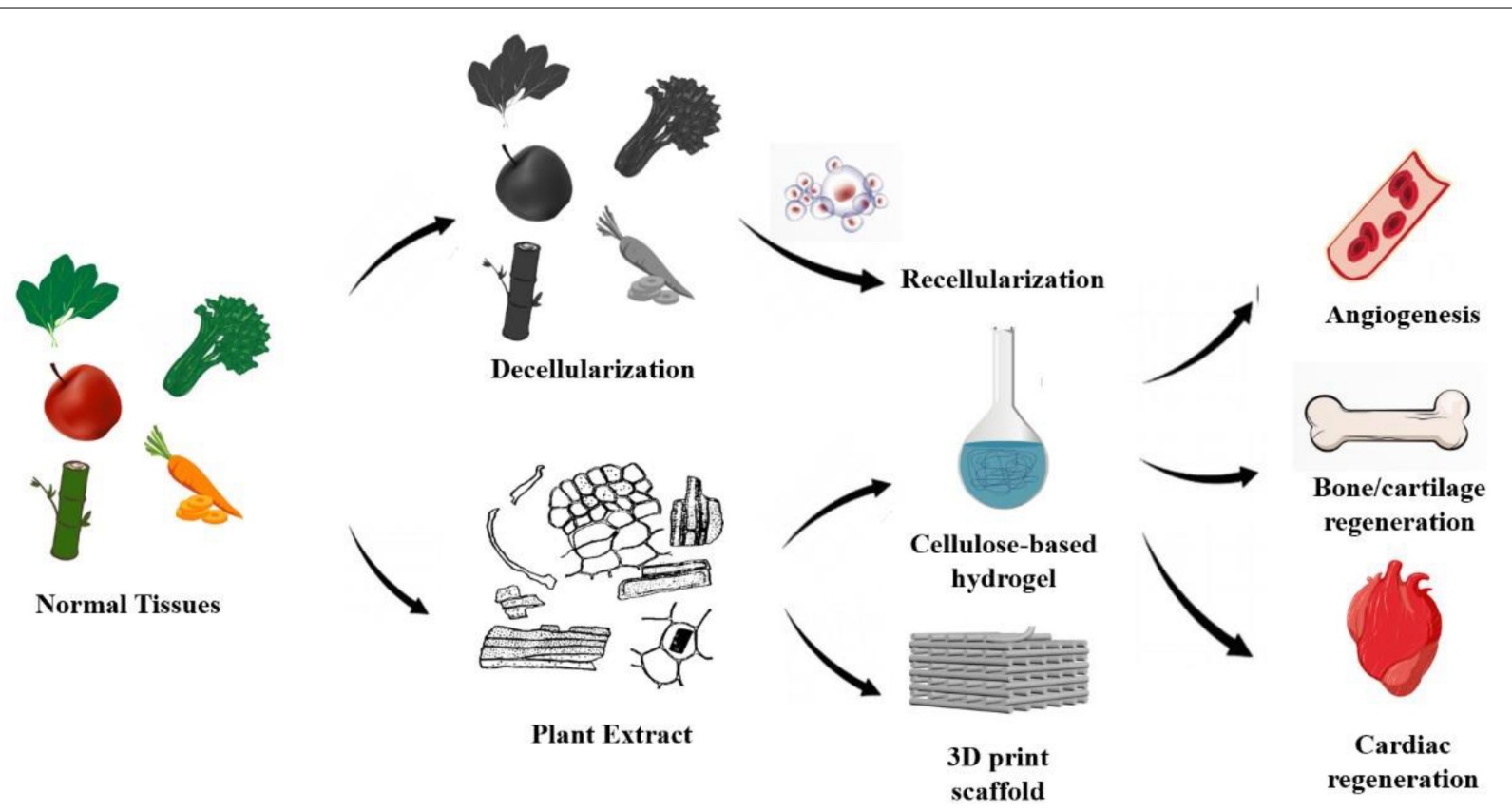

FIGURE 3 | Preparation and application of decellularized plant scaffolds: Current bioactive plant-derived scaffolds (1) recellularization of decellularized plant scaffolds, (2) plant extracts were used for cardiovascular regeneration and bone tissue regeneration by gelation and 3D printing. 
After 3 weeks of culture in the osteogenic induction medium, the pluripotent stem cells on the decellularized apple scaffold showed obvious osteogenic differentiation. In addition, after the transplantation into the rat skull defect model, the scaffold significantly promoted the healing of defects in vivo, and had the potential to support vascular growth for bone regeneration (Lee et al., 2019). However, in the current research, decellularized plant scaffolds only provide a porous three-dimensional growth space for cells, and the scaffold itself does not directly promote bone healing function. At present, some plant extracts have been found to have the potential to promote osteogenesis and to regulate immune response. For example, garlic contains a large number of pharmaceutically active sulfur compounds, which can reduce the clinical symptoms of gingivitis (Rodrigues and Percival, 2019); a paste prepared from quinoa leaves, which have a large content of saponins, flavonoids, tannins, and alkaloids, may contribute to its effect on bone regeneration (Pinheiro Neto et al., 2017). Therefore, constructing natural decellularized scaffolds with osteogenic activity will be the future research direction.

\section{Decellularized Plant Scaffold for Muscle Regeneration}

Some common fruits or vegetables with unique architectures are suited for muscle alignment. Since voluntary striated muscle fibers are arranged in bundles parallel to each other in human body, plant scaffolds with anisotropic structures when cut longitudinally versus transverse are required, such as leek, asparagus, green onion and celery (Cheng et al., 2020). Cheng et al. (2020) seeded human skeletal muscle cells on green onion-derived cellulose scaffolds. Cells aligned perfectly on the outer white bulb-derived cellulose scaffolds after 6 days. They also found that repeating grooves with $20 \mu \mathrm{m}$ wide, $10 \mu \mathrm{m}$ deep, and $5 \mu \mathrm{m}$ spacing seems to be the most appropriate topography to generate an aligned muscle cell monolayer (Cheng et al., 2020). However, the study of decellularized plant scaffolds for muscle regeneration are limited to in vitro at present, and a large number of studies are needed for future application in vivo, such as how to achieve the maximum differentiation of muscle cells on the scaffold, and how to ensure that the synthesized skeletal muscle tissue has sufficient contractile strength.

\section{CONCLUSION}

Plant scaffold not only has the characteristics of animal architecture but also provides the $3 \mathrm{D}$ environment and vascular system needed by stem cells. Moreover, it has good modifiability, which makes it suitable for the proliferation and differentiation of a variety of stem cells and can promote the development and differentiation of blood vessels. Nano scale fine structure

\section{REFERENCES}

Adamski, M., Fontana, G., Gershlak, J. R., Gaudette, G. R., Le, H. D., and Murphy, W. L. (2018). Two methods for decellularization of plant tissues for tissue engineering applications. J. Vis. Exp. 1:57586. doi: 10.3791/57586 plant framework is used for in vivo organ or tissue regeneration and in vitro tissue regeneration research and clinical application, which provides rare precise organ tissue engineering materials.

The application of decellularized plant scaffold is still in its infancy. The characteristics of plant tissue materials lay a foundation for its application. (1) The diversity of plant structure and composition allows for the construction of decellularized scaffolds suitable for different organs. (2) A plant framework has many advantages over an animal framework; it is characterized by good modification, no pollution or pathogens, a low cost and a simple production process, making it suitable for large-scale production and basic research. (3) The striking similarity between plant tissue and some organs of the human body promise its good prospect for application in vivo and in vitro. However, many challenges still need to be overcome in the clinical application of decellularized plant scaffolds. (1) The existing decellularization methods will greatly damage the structure of plants, including the increase of pores and the decrease of mechanical properties. Therefore, the decellularization methods suitable for plants, especially for some fragile tissues, are in urgent need of research. (2) Due to the lack of cellulase in animals, plant scaffolds can hardly be degraded in vivo and the existing methods may have negative effects on the scaffolds. (3) The evaluation methods of the biocompatibility of plant scaffolds are not clear yet, and there are few studies on the immune process caused by plant scaffolds in vivo. (4) The current decellularized plant scaffolds only provide a three-dimensional scaffold for cell growth, but their biological activity is poor. Therefore, it is a feasible research direction to endow the scaffold with corresponding biological activity by coating and other methods.

\section{AUTHOR CONTRIBUTIONS}

All authors listed have made a substantial, direct and intellectual contribution to the work, and approved it for publication.

\section{FUNDING}

This study was supported by the National Key R\&D Program of China (Grant Number 2020YFC1107102), the National Nature Science Fund of China (Grant Number 82072414), and Public Projects of Zhejiang Province (LGF19H060013). Innovative Talent Support Program of Zhejiang Provincial Health Commission (Grant Number 2021433298). Zhejiang Provincial Program for the cultivation of high-level innovative health talents. Wen Zhou Major scientific and Technological Innovation project (2018ZY015). Wen zhou Basic Medical and Health Project (Y2020238).

Albenne, C., Canut, H., Hoffmann, L., and Jamet, E. (2014). Plant cell wall proteins: a large body of data, but what about runaways? Proteomes 2, 224-242. doi: $10.3390 /$ proteomes2020224

Altman, G. H., Diaz, F., Jakuba, C., Calabro, T., Horan, R. L., Chen, J., et al. (2003). Silk-based biomaterials. 
Biomaterials 24, 401-416. doi: 10.1016/s0142-9612(02)00 353-8

Author Anonymous (2021). OPTN/SRTR. Am. J. Transplant. 21 (Suppl 2), 11-20.* doi: 10.1111/ajt.16493

Badylak, S. F., and Gilbert, T. W. (2008). Immune response to biologic scaffold materials. Semin. Immunol. 20, 109-116. doi: 10.1016/j.smim.2007.11.003

Badylak, S. F., Freytes, D. O., and Gilbert, T. W. (2009). Extracellular matrix as a biological scaffold material: Structure and function. Acta Biomater. 5, 1-13. doi: 10.1016/j.actbio.2008.09.013

Bush, J. R., Liang, H., Dickinson, M., and Botchwey, E. A. (2016). Xylan hemicellulose improves chitosan hydrogel for bone tissue regeneration. Polym Adv. Technol. 27, 1050-1055. doi: 10.1002/pat.3767

Caamaño, S., Shiori, A., Strauss, S. H., and Orton, E. C. (2009). Does sodium dodecyl sulfate wash out of detergent-treated bovine pericardium at cytotoxic concentrations? J. Heart Valve Dis. 18, 101-105.

Caffall, K. H., and Mohnen, D. (2009). The structure, function, and biosynthesis of plant cell wall pectic polysaccharides. Carbohydr. Res. 344, 1879-1900. doi: 10.1016/j.carres.2009.05.021

Chakraborty, J., Roy, S., and Ghosh, S. (2020). Regulation of decellularised matrix mediated immune response. Biomater. Sci. 8, 1194-1215. doi: 10.1039/ c9bm01780a

Cheng, Y. W., Shiwarski, D. J., Ball, R. L., Whitehead, K. A., and Feinberg, A. W. (2020). Engineering aligned skeletal muscle tissue using decellularized plant-derived scaffolds. ACS Biomater. Sci. Eng. 6, 3046-3054. doi: 10.1021/ acsbiomaterials.0c00058

Contessi Negrini, N., Toffoletto, N., Farè, S., and Altomare, L. (2020). Plant tissues as $3 \mathrm{~d}$ natural scaffolds for adipose, bone and tendon tissue regeneration. Front. Bioeng. Biotechnol. 8:723. doi: 10.3389/fbioe.2020.00723

Czaja, W. K., Young, D. J., Kawecki, M., and Brown, R. M. Jr. (2007). The future prospects of microbial cellulose in biomedical applications. Biomacromolecules 8, 1-12. doi: 10.1021/bm060620d

Czaja, W., Krystynowicz, A., Bielecki, S., and Brown, R. M. (2006). Microbial cellulose-the natural power to heal wounds. Biomaterials 27, 145-151. doi: 10.1016/j.biomaterials.2005.07.035

Dimitrijevich, S. D., Tatarko, M., Gracy, R. W., Wise, G. E., Oakford, L. X., Linsky, C. B., et al. (1990b). in vivo degradation of oxidized, regenerated cellulose. Carbohydr. Res. 198, 331-341. doi: 10.1016/0008-6215(90)84303-c

Entcheva, E., Bien, H., Yin, L., Chung, C. Y., Farrell, M., and Kostov, Y. (2004). Functional cardiac cell constructs on cellulose-based scaffolding. Biomaterials. 25, 5753-5762. doi: 10.1016/j.biomaterials.2004.01.024

Fang, H. Y., Chen, Y. K., Chen, H. H., Lin, S. Y., and Fang, Y. T. (2012). Immunomodulatory effects of feruloylated oligosaccharides from rice bran. Food Chem. 134, 836-840. doi: 10.1016/j.foodchem.2012.02.190

Fernandes, A. N., Thomas, L. H., Altaner, C. M., Callow, P., Forsyth, V. T., Apperley, D. C., et al. (2011). Nanostructure of cellulose microfibrils in spruce wood. Proc. Natl Acad. Sci. USA 108, E1195-E1203. doi: 10.1073/pnas. 1108942108

Fontana, G., Gershlak, J., Adamski, M., Lee, J. S., Matsumoto, S., Le, H. D., et al. (2017). Biofunctionalized Plants as Diverse Biomaterials for Human Cell Culture. Adv. Healthc. Mater. 6:10.1002/adhm.201601225.

Frantz, C., Stewart, K. M., and Weaver, V. M. (2010). The extracellular matrix at a glance. J. Cell Sci. 123(Pt 24), 4195-4200. doi: 10.1242/jcs.023820

From the American Association of Neurological Surgeons (Aans), American Society of Neuroradiology (Asnr), Cardiovascular and Interventional Radiology Society of Europe (Cirse), Canadian Interventional Radiology Association (Cira), Congress of Neurological Surgeons (Cns), European Society of Minimally Invasive Neurological Therapy (Esmint), et al. (2018). Multisociety consensus quality improvement revised consensus statement for endovascular therapy of acute ischemic stroke. Int. J. Stroke 13, 612-632. doi: 10.1177/ 1747493018778713

Gershlak, J. R., Hernandez, S., Fontana, G., Perreault, L. R., Hansen, K. J., Larson, S. A., et al. (2017). Crossing kingdoms: Using decellularised plants as perfusable tissue engineering scaffolds. Biomaterials 125, 13-22. doi: 10.1016/j. biomaterials.2017.02.011

Guler, S., Aslan, B., Hosseinian, P., and Aydin, H. M. (2017). Supercritical carbon dioxide-assisted decellularization of aorta and cornea. Tissue Eng. Part C Methods. 23, 540-547. doi: 10.1089/ten.TEC.2017.0090
Harris, A. F., Lacombe, J., Liyanage, S., Han, M. Y., Wallace, E., Karsunky, S., et al. (2021). Supercritical carbon dioxide decellularization of plant material to generate 3D biocompatible scaffolds. Sci. Rep. 11, 3643. doi: 10.1038/s41598021-83250-9

Hori, R., Muller, M., Watanabe, U., Lichtenegger, H. C., Fratzl, P., and Sugiyama, J. (2002). The importance of seasonal differences in the cellulose microfibril angle in softwoods in determining acoustic properties. J. Mater. Sci. 37, 4279-4284. doi: 10.1023/A:1020688132345

Horn, S. J., Vaaje-Kolstad, G., Westereng, B., and Eijsink, V. G. (2012). Novel enzymes for the degradation of cellulose. Biotechnol. Biofuels. 5:45. doi: 10.1186/ 1754-6834-5-45

Huerta, S., Varshney, A., Patel, P. M., Mayo, H. G., and Livingston, E. H. (2016). Biological mesh implants for abdominal hernia repair: us food and drug administration approval process and systematic review of its efficacy. JAMA Surg. 151, 374-381. doi: 10.1001/jamasurg.2015.5234

Hurtado-López, P., and Murdan, S. (2006). An investigation into the adjuvanticity and immunogenicity of zein microspheres being researched as drug and vaccine carriers. J. Pharm. Pharmacol. 58, 769-774. doi: 10.1211/jpp.58.6.0007

Jansen, K., Evangelopoulou, M., Pou Casellas, C., Abrishamcar, S., Jansen, J., Vermonden, T., et al. (2020). Spinach and chive for kidney tubule engineering: the limitations of decellularized plant scaffolds and vasculature. AAPS J. 23:11. doi: 10.1208/s12248-020-00550-0

Johnson, M. (2013). Detergents: tTriton X-100, tTween-20, and mMore. Mater. Methods 3:163. doi: 10.13070/mm.en.3.163

Kular, J. K., Basu, S., and Sharma, R. I. (2014). The extracellular matrix: sStructure, composition, age-related differences, tools for analysis and applications for tissue engineering. J. Tissue Eng. 5:2041731414557112. doi: 10.1177/ 2041731414557112

Kumar, V., and Yang, D. (2002). HNO3/H3PO4-NANO2 mediated oxidation of cellulose-preparation and characterization of bioabsorbable oxidized celluloses in high yields and with different levels of oxidation. Carbohydr. Polym. 48, 403-412. doi: 10.1016/s0144-8617(01)00290-9

Lacombe, J., Harris, A. F., Zenhausern, R., Karsunsky, S., and Zenhausern, F. (2020). Plant-based scaffolds modify cellular response to drug and radiation exposure compared to standard cell culture models. Front. Bioeng. Biotechnol. 8:932. doi: 10.3389/fbioe.2020.00932

Lee, J., Jung, H., Park, N., Park, S. H., and Ju, J. H. (2019). Induced osteogenesis in plants decellularised scaffolds. Sci. Rep. 9:20194.

Liuyun, J., Yubao, L., and Chengdong, X. (2009). Preparation and biological properties of a novel composite scaffold of nanohydroxyapatite/chitosan/carboxymethyl cellulose for bone tissue engineering. J. Biomed. Sci. 16:65. doi: 10.1186/1423-0127-16-65

Mathew, A. P., Oksman, K., Pierron, D., and Harmand, M. F. (2012). Fibrous cellulose nanocomposite scaffolds prepared by partial dissolution for potential use as ligament or tendon substitutes. Carbohydr. Polym. 87, 2291-2298. doi: 10.1016/j.carbpol.2011.10.063

McCulloh, K. A., Sperry, J. S., and Adler, F. R. (2003). Water transport in plants obeys Murray's law. Nature. 421, 939-942. doi: 10.1038/nature01444

Miyamoto, T., Takahashi, S., Ito, H., Inagaki, H., and Noishiki, Y. (1989). Tissue biocompatibility of cellulose and its derivatives. J. Biomed. Mater. Res. 23, 125-133. doi: 10.1002/jbm.820230110

Modulevsky, D. J., Cuerrier, C. M., and Pelling, A. E. (2016). Biocompatibility of Subcutaneously Implanted Plant-Derived Cellulose Biomaterials. PLoS One 11:e0157894. doi: 10.1371/journal.pone.0157894

Modulevsky, D. J., Lefebvre, C., Haase, K., Al-Rekabi, Z., and Pelling, A. E. (2014). Apple derived cellulose scaffolds for 3D mammalian cell culture. PLoS One 9:e97835. doi: 10.1371/journal.pone.0097835

Müller, F. A., Müller, L., Hofmann, I., Greil, P., Wenzel, M. M., and Staudenmaier, R. (2006). Cellulose-based scaffold materials for cartilage tissue engineering. Biomaterials 27, 3955-3963. doi: 10.1016/j.biomaterials.2006.02.031

Murray, C. D. (1926). The physiological principle of minimum work: i. the vascular system and the cost of blood volume. Proc. Natl. Acad. Sci. U.S.A. 12, 207-214. doi: $10.1073 /$ pnas. 12.3 .207

Nara, S., Chameettachal, S., Midha, S., Murab, S., and Ghosh, S. (2016). Preservation of biomacromolecular composition and ultrastructure of a decellularized cornea using a perfusion bioreactor. RSC Adv. 6, 2225-2240. doi: 10.1039/C5RA20745B 
Niehaus, T. D., Thamm, A. M., de Crécy-Lagard, V., and Hanson, A. D. (2015). Proteins of unknown biochemical function: a persistent problem and a roadmap to help overcome it. Plant Physiol. 169, 1436-1442. doi: 10.1104/pp.15.00959

Peng, X. Y., Hu, M., Liao, F., Yang, F., Ke, Q. F., Guo, Y. P., et al. (2019). La-Doped mesoporous calcium silicate/chitosan scaffolds for bone tissue engineering. Biomater. Sci. 7, 1565-1573. doi: 10.1039/c8bm01498a

Peura, M., Muller, M., Vainio, U., Saren, M.-P., Saranpaa, P., and Serimaa, R. (2008). X-ray microdiffraction reveals the orientation of cellulose microfibrils and the size of cellulose crystallites in single Norway spruce tracheids. Trees 22, 49-61. doi: 10.1007/s00468-007-0168-5

Phan, N. V., Wright, T., Rahman, M. M., Xu, J., and Coburn, J. M. (2020). in vitro biocompatibility of decellularized cultured plant cell-derived matrices. ACS Biomater. Sci. Eng.. 6, 822-832. doi: 10.1021/acsbiomaterials.9b00870

Pinheiro Neto, V. F., Ribeiro, R. M., Morais, C. S., Campos, M. B., Vieira, D. A., Guerra, P. C., et al. (2017). Chenopodium ambrosioides as a bone graft substitute in rabbits radius fracture. BMC Complement. Altern. Med. 17:350. doi: 10.1186/s12906-017-1862-5

Ponnusamy, V. K., Nguyen, D. D., Dharmaraja, J., Shobana, S., Banu, J. R., Saratale, R. G., et al. (2019). A review on lignin structure, pretreatments, fermentation reactions and biorefinery potential. Bioresour. Technol. 271, 462-472. doi: 10. 1016/j.biortech.2018.09.070

Reddy, N., and Yang, Y. (2011). Potential of plant proteins for medical applications. Trends Biotechnol. 29, 490-498. doi: 10.1016/j.tibtech.2011.05.003

Rodrigues, C., and Percival, S. S. (2019). Immunomodulatory effects of glutathione, garlic derivatives, and hydrogen sulfide. Nutrients 11:295. doi: 10.3390/ nu11020295

S H, A., Mohan, C. C., P S, U., Krishnan, A. G., and Nair, M. B. (2021). Decellularization and oxidation process of bamboo stem enhance biodegradation and osteogenic differentiation. Mater. Sci. Eng. C Mater. Biol. Appl. 119:111500. doi: 10.1016/j.msec.2020.111500

Saito, T., Kimura, S., Nishiyama, Y., and Isogai, A. (2007). Cellulose nanofibers prepared by TEMPO-mediated oxidation of native cellulose. Biomacromolecules 8, 2485-2491. doi: 10.1021/bm0703970

Seba, A. (1730). III The anatomical preparation of vegetables, by Albertus Seba, F. R. S. Communicated to the Royal Society by Sir Hans Sloane, Bart. Pr. R. S. and Col. Med. Lond. Translated from the German, by Mr. Zolman, F. R. SPhil. Trans. R. Soc. 36, 441-444. doi: 10.1098/rstl.1729.0061

Silva, G. A., Vaz, C. M., Coutinho, O. P., Cunha, A. M., and Reis, R. L. (2003). in vitro degradation and cytocompatibility evaluation of novel soy and sodium caseinate-based membrane biomaterials. J. Mater. Sci. Mater. Med. 14, 10551066. doi: 10.1023/b:jmsm.0000004002.11278.30

Syed, O., Walters, N. J., Day, R. M., Kim, H. W., and Knowles, J. C. (2014). Evaluation of decellularization protocols for production of tubular small intestine submucosa scaffolds for use in oesophageal tissue engineering. Acta Biomater. 10, 5043-5054. doi: 10.1016/j.actbio.2014.08.024

Waghmare, N. A., Arora, A., Bhattacharjee, A., and Katti, D. S. (2018). Sulfated polysaccharide mediated TGF- $\beta 1$ presentation in preformed injectable scaffolds for cartilage tissue engineering. Carbohydr Polym. 193, 62-72. doi: 10.1016/j. carbpol.2018.03.091

Wegst, U. G., Bai, H., Saiz, E., Tomsia, A. P., and Ritchie, R. O. (2015). Bioinspired structural materials. Nat. Mater. 14, 23-36. doi: 10.1038/nmat4089

Zablackis, E., Huang, J., Müller, B., Darvill, A. G., and Albersheim, P. (1995). Characterization of the cell-wall polysaccharides of Arabidopsis thaliana leaves. Plant Physiol. 107, 1129-1138. doi: 10.1104/pp.107.4.1129

Zaborowska, M., Bodin, A., Bäckdahl, H., Popp, J., Goldstein, A., and Gatenholm, P. (2010). Microporous bacterial cellulose as a potential scaffold for bone regeneration. Acta Biomater. 6, 2540-2547. doi: 10.1016/j.actbio.2010.01.004

Zhang, Y., Jiang, M., Zhang, Y., Cao, Q., Wang, X., Han, Y., et al. (2019). Novel lignin-chitosan-PVA composite hydrogel for wound dressing. Mater. Sci. Eng. C Mater. Biol. Appl. 104:110002. doi: 10.1016/j.msec.2019.110002

Zhou, S., Liu, X., Guo, Y., Wang, Q., Peng, D., and Cao, L. (2010). Comparison of the immunological activities of arabinoxylans from wheat bran with alkali and xylanase-aided extraction. Carbohydrate Polymers. 81, 784-789. doi: 10.1016/j. carbpol.2010.03.040

Zimnitsky, D. S., Yurkshtovich, T. L., and Bychkovsky, P. M. (2004). Synthesis and characterization of oxidized cellulose. J. Polym. Sci. A Polym. Chem. 42, 4785-4791.

Conflict of Interest: The authors declare that the research was conducted in the absence of any commercial or financial relationships that could be construed as a potential conflict of interest.

Copyright (c) 2021 Zhu, Zhang, Wang, Zhang, Fan and Lin. This is an open-access article distributed under the terms of the Creative Commons Attribution License (CC BY). The use, distribution or reproduction in other forums is permitted, provided the original author(s) and the copyright owner(s) are credited and that the original publication in this journal is cited, in accordance with accepted academic practice. No use, distribution or reproduction is permitted which does not comply with these terms. 